Predicting the economic impacts of the 2017 West Coast salmon troll ocean fishery closure

Kate Richerson ${ }^{1,2}$, Jerry Leonard ${ }^{3}$, Daniel S. Holland ${ }^{4}$

${ }^{1}$ ECS Federal, under contract to NOAA Fisheries, Northwest Fisheries Science Center, 2725 Montlake Blvd E., Seattle, WA 98112, USA

${ }^{2}$ Current affiliation: School of Aquatic and Fisheries Sciences, University of Washington, 1122 NE Boat St, Seattle, WA 98105, USA

${ }^{3}$ NOAA Fisheries, Fishery Resource Analysis and Monitoring Division, Northwest Fisheries Science Center, 2725 Montlake Blvd E., Seattle, WA 98112, USA

${ }^{4}$ NOAA Fisheries, Conservation Biology Division, Northwest Fisheries Science Center, 2725 Montlake Blvd E., Seattle, WA 98112, USA

Key words: salmon fishery, California Current, fishery disaster, fishery closure, economic impacts, fishing behavior, input-output model

Corresponding author:

Kate Richerson

Email: katericherson@gmail.com

Phone: +1 2063022422 


\title{
Predicting the economic impacts of the 2017 West Coast salmon troll ocean fishery closure
}

\begin{abstract}
The ocean salmon fishery on the US West Coast has faced periodic closures of varying extents in order to protect vulnerable runs. These closures can have serious consequences for fishers and fishing communities, and have necessitated the release of millions of dollars of federal disaster aid. The 2017 ocean Chinook troll fishery (the major salmon ocean fishery) is closed between southern Oregon and northern California to protect the Klamath River fall Chinook, which is forecast to return in low numbers. A model of vessel fishing choices was used in combination with an established input-output model to estimate the potential economic impact of this closure on fishers and fishing communities. The analysis predicts that this closure of the ocean fishery will result in a loss of \$5.8-\$8.9 million in income, $\$ 12.8-\$ 19.6$ million in sales, and $200-330$ jobs. These estimates are only a partial estimate of the economic impacts of the 2017 salmon regulations, as they do not fully account for the effects of the limited season outside of the closed ocean area or the effects on other salmon fisheries (e.g. the gillnet and recreational fisheries). The impacts are not distributed evenly in space, with the largest relative losses occurring in the Coos Bay, Brookings, and Eureka regions. This information may be useful as policymakers consider mitigating economic losses in the fishery and associated communities. Early estimates of economic impacts of fishery closures may also enable quicker determination of the need and extent of disaster assistance and a more timely response.
\end{abstract}

Key words: salmon fishery, California Current, fishery disaster, fishery closure, economic impacts, fishing behavior, input-output model

\section{Introduction}

The US West Coast ocean salmon troll fishery is a major fishery in the region, with annual nominal ex-vessel landings valued at $\$ 12.4$ to $\$ 35.8$ million over the past 5 years (Figure 1). The ocean fishery is a mixed-stock fishery, and the season is typically structured to limit the impacts of harvest on weaker stocks, some of which are protected 45 under the Endangered Species Act. As a result, the fishery has faced multiple closures of 46 various extents over the past several decades. For example, in 2008 and 2009, the fishery 
was closed completely south of Cape Falcon, Oregon following the collapse of the

48 Sacramento River fall Chinook, which historically provided $80-85 \%$ of ocean catches in

49 California [1]. This resulted in the declaration of a federal disaster and the release of other salmon-dependent businesses. Two other partial closures in 2006 and 2010 affected smaller portions of the coast (see Figure 2 and Table 1 for an overview of all recent spatial closures).

[Figures 1,2 and Table 1 about here]

On the West Coast, most fishermen participate in a variety of fisheries, which may help buffer against the short-term (annual to decadal) variability of stocks. Fisher cross-participation thus connects harvested species and human communities that are not directly linked ecologically, and changes in fishing behavior have the potential to either amplify or dampen the effects of biological variation. Though theory suggests that fishermen may shift some or all of their effort into alternate fisheries when other stocks are scarce, Richerson and Holland [2] found that in the case of the 2008-2009 salmon ocean fishery closure, most salmon trollers did not increase their participation in other fisheries. Instead, nearly half of the fleet ceased fishing entirely during the closure, meaning they did not participate in salmon fishing or any other fishery (including fisheries that they typically participated in prior to the closure). This may be because they could not recoup their costs (e.g. crew, fuel, repairs) if they did fish and/or because alternate sources of income outside of fishing became more attractive. This resulted in $\sim \$ 45$ million in lost landings revenue, of which $\sim \$ 35$ million could be attributed to lost salmon revenue and the remaining to revenue lost from other fisheries. This loss had serious implications for fishers, fishing-dependent businesses, and local fishing communities [3]. These results also indicate that though many fishermen have somewhat diversified fishing portfolios, their ability to offset losses is limited because of the seasonality of fisheries (i.e. there may be few substitutable options during the regular salmon season) and limited-entry regulations (i.e. fishermen cannot move into most fisheries without owning or purchasing an existing permit). Acknowledging these complexities of fisher behavior is key for fishery sustainability and management $[4,5]$.

Over the past several years, both marine and freshwater salmon habitat conditions have generally been poor for salmon growth and survival. The severe drought of 2011 to 2017 likely reduced freshwater survival for many runs [e.g. 6, 7], and the marine heatwave of 2013-2015 known as "the Blob" resulted in higher sea surface temperatures and reduced productivity across much of California Current [8]. In addition, the Pacific Decadal Oscillation shifted to a positive phase in 2014, which historically has been linked to lower salmon production for West Coast stocks [9-11]. Salmon catches have been declining since 2012, and in April 2017 the Pacific Marine Fisheries Council recommended closing the ocean fishery between the Florence, Oregon to Horse Mountain, California. This was precipitated by record low returns of the Klamath River fall Chinook. In June of 2017, the Governors of California and Oregon asked the Secretary of Commerce to declare the salmon fishery a catastrophic regional disaster in 912016 and 2017. 
Quantifying the impact of a poor fishing season can be difficult, as fishers may adjust their behavior in unexpected ways, and this in turn may affect fishing-dependent businesses and communities. Here, a modified version of an existing model of West Coast salmon troller behavior [2] in combination with an established input-output model was used to create a spatially-explicit estimate of the lost income, jobs, and sales that are likely to be associated with the 2017 salmon closure. Disaster assistance is often subject to long delays and is not available when it is most needed. For example, in the case of the 2005-2006 salmon disaster in California and Oregon, aid funds were not appropriated until May 2007, and distributed beginning August 2007 through March 2008 [12]. In several other cases, fishermen have waited several years for a decision, only to have their

\section{Methods}

\subsection{Overview}

A vessel-based approach was used to model the impact of a fishery closure. First, the group of vessels that participated in salmon troll fishing prior to the closures that occurred between 2006 and 2010 was identified. The probability that a vessel will participate in fishing of any kind, and if so, if it will participate in salmon troll fishing in each year was modeled, based on the presence of a closure and characteristics of the vessel. This set of behavioral models (parameterized on vessels' responses to the 20062010 closures) was then used to make predictions about the vessels identified as salmon trollers in more recent years. Specifically, the probability they will fish in 2017 was estimated, and if so, the probability that they will participate in the salmon troll fishery given the extent of the current closure. Finally, an input-output model was used to estimate the economic impact of this predicted behavior, on income, employment, and sales. To quantify uncertainty, a Monte Carlo approach was used, where vessels behave probabilistically according to the models.

\subsection{Vessel identification and characteristics}

Most vessels that participate in the ocean salmon troll fishery participate in multiple fisheries. In order to identify relevant vessels, vessels were selected that were active in the salmon troll fishery prior to 2006 (when the first spatial closure in the past several years was put into place). These vessels met two simple criteria: 1) They made at least $\$ 1,000$ from salmon troll fishing during 2001-2005, and 2) they fished at least 2 years during 2001-2005. These vessels are referred to as the 2001-2005 vessels. These vessels, and their response to the 2006, 2008, 2009, and 2010 closures were used to parameterize a participation model designed to predict response to fishery closures.

The composition of vessels that participate in the current fishery has changed since the early 2000 s, especially since many vessels active in salmon trolling then left the fishery after the large-scale closures of 2008-9 [2]. Thus, the current group of focal vessels was defined as any vessel that made $\$>1,000$ from salmon troll 2012-2016 and 
fished at least 2 years in that period. These are referred to as the 2012-2016 vessels. The participation models parameterized using the 2001-2005 vessels were then used to predict the responses of the 2012-2016 vessels to the 2017 partial salmon fishery closure.

\subsection{Choice to fish}

Not all vessels participate in fishing every year, and presence of a closure may affect whether a vessel chooses to go fishing in a given year. A modified version of the model of [2], which predicts whether or not a vessel will participate in fishing in a given year based on vessel characteristics and the presence of a spatial fishery closure, was used to model the choice to fish. Though [2] focused on the large-scale 2008-2009 salmon troll fishery closure, the modified version incorporates information from the smaller-scale closures of 2006 and 2010 to inform predictions about the current closure. First, a broad cohort of vessels active in the salmon troll fishery over 2001-2005 (the years before the 2006 closure) was identified. Any vessel that 1) averaged over $\$ 1000$ in annual revenue from salmon troll fishing 2) fished at least 2 years in this period was included in the cohort. Next, a set of vessel characteristics were identified that may predict responses to a closure. Chosen vessel characteristics include latitudinal center of gravity (LCG; a measure of fishing location along the coast), latitudinal inertia (LI, a measure of spatial range), mean total inflation-adjusted revenue, revenue diversification (in terms of inverse Herfindahl-Hirschman index; HHI), and percent of total revenue from salmon troll fishing. For details of how vessel characteristics were selected and calculated, see [2]. To account for the impact of a spatial closure, a dummy variable was included that takes on a value of 1 if a given vessel's LCG was inside a closed area in a given year and 0 if not. Thus, the expected probability $p_{y i}$ that vessel $i$ participates in fishing (salmon troll and/or other fisheries) in year $y$ was modeled using a binomial generalized linear mixed model with a complimentary log-log link and a vessel-level random intercept as

$\log \left(-\log \left(1-p_{y i}\right)=\alpha+\beta_{1} y+\beta_{2} L C G\right.$.in.closure ${ }_{i}+\beta_{3}$ revenue $_{i}+\beta_{4} H H_{i}+\beta_{5}$ percent.troll $_{i}+\beta_{6} L C G_{i}+$ $\beta_{7} L_{i}+\beta_{8}$ years. fished ${ }_{i}+\beta_{9}$ LCG.in.closure $_{i} \cdot$ revenue $_{i}+\beta_{10}$ LCG.in.closure $_{i} \cdot H H I_{i}+$

$\beta_{11} L^{L C G . i n . c l o s u r e}{ }_{i} \cdot$ percent.troll $_{i}+\beta_{12}$ LCG.in.closure $_{i} \cdot L C G_{i}+\beta_{13}$ LCG.in.closure $_{i} \cdot L I_{i}+$ $\beta_{14}$ LCG.in.closure ${ }_{i} \cdot$ years. fished $_{i}+a_{i}$

166

167

168

169

170

171

172

173

174

175

176

177

178

179

180 where $a_{i}$ is the normally-distributed random intercept term with mean zero. The complimentary log-log link was chosen because it can take on an asymmetrical shape, allowing uneven numbers of ones and zeroes [14]. Year was defined as the number of years since defining the focal vessels (i.e. years since 2001). If a vessel does fish in that year, the probability it participates in the salmon troll fishery was modeled using the same model structure as above. To aid in model fitting and interpretation, we centered and scaled all continuous variables [15]. Area under curve (AUC) of the receiver operating characteristic (ROC) was used to evaluate model fits [16]. To construct the ROC $k$-fold cross-validation was used, where vessels were randomly divided into groups of 100, the model trained on all but one group, then tested on the selected group. This process was then repeated for each group. To evaluate model performance a common rule of thumb was used where AUC 0.6 is failed, $0.6<$ AUC 0.7 is poor, $0.7<$ AUC 0.8 is fair, $0.8<$ AUC 0.9 is good, and $0.9<$ AUC 1.0 is excellent. 


\subsection{Predicted participation and revenue}

182 Vessel characteristics for the 2012-2016 vessel group were used to predict fishery

183 participation in 2017 using the models described above. To do so, for each focal vessel

184 the predicted probability of fishing was estimated as well as the predicted probability of

185 participating in the salmon troll fishery if the vessel does go fishing. To characterize the

186 uncertainty around the predictions, 10,000 Monte Carlo simulations were performed

187 where vessels were allowed to fish (or not) according to their predicted probabilities. The

188 total revenue from each species/gear group landed in each area was then calculated, based

189 on the vessels that are predicted to be active. No salmon troll catches were assumed to be

190 landed inside the closed area. Outside the closed areas, vessel revenue in each area, species, and gear group was assumed to be equal to the vessel's past 5-year average. This was done under both closure and non-closure scenarios, allowing comparison of the predicted distribution of income, employment, and sales in each area under each scenario. An alternate deterministic approach was also used where vessel participation was predicted based on an optimal classification threshold $c$, which accounts for the possibility of bias towards false positives or false negatives in the model predictions. In this case, vessels were predicted to fish when $p_{y i}>c$, where $c$ is the value that that equalizes model sensitivity (true positive rate) and specificity (true negative rate). Predicted revenues were then calculated as above.

\subsection{Input/output model}

Input-output models are commonly used to estimate the wider economic impacts of output from a particular sector. While input-output models were originally used for quantifying the economic effects of exogenous final demand shocks, they are appropriate for use in situations of exogenous output changes, such as a change in fishing output, provided proper adjustments are made [17]. The input-output model for Pacific Coast Fisheries [IO-PAC; 18] was used to translate predicted ex-vessel revenue into spatiallyexplicit measures of income, sales, and employment associated with the focal vessels. The IO-PAC model was designed to estimate the economic impacts resulting from policy, environmental, or other changes that affect fishery harvest. The model was constructed by customizing Impact Analysis for Planning (IMPLAN) regional inputoutput (IO) software (IMPLAN, MIG Inc. Hudson Wisconsin). Development of IO-PAC included customizing IMPLAN with an addition of 19 commercial fishing vessel types that produce 32 unique species and gear outputs. The model is spatially flexible and impact estimates can be generated for 18 different port study areas.

Economic impact estimates include the effects of changes in fish harvest on sales, income, and employment by harvesting vessels and processors. In this case, sales is defined as the estimated dollar value of production in the region summed across all industries and includes both final purchases and intermediate purchases that are used in the production of goods and services. Income is defined as all forms of employment and proprietor income (wages and benefits) generated by businesses directly or indirectly linked to fishers and processors. 
Employment includes all full or part-time jobs generated by businesses directly or indirectly linked to the fishing industry. A change in vessel revenue not only affects the direct number of crew member positions on vessels, it also affects employment in businesses sectors that supply goods and services to fishing vessels. Additionally, changes in vessel revenue that results in changes in income affects household spending.

\section{Results} affected by changes in household spending.

\subsection{Focal vessels}

1,585 vessels were identified that participated in the salmon troll fishery 2001-2005 and 1,505 that participated in the fishery 2012-2016, with 875 vessels appearing in both groups. This indicates that about half of the 2001-2005 group either stopped participating in the salmon troll fishery or stopped fishing entirely by 2012-2016. The salmon troll fishery is a limited entry fishery (with state-issued permits), but permits are transferable. It appears that many of the permits that had been held by vessels that exited the fishery following the 2008-2009 were purchased and activated by new entrants. The vessel groups identified are responsible for $>98 \%$ of the total salmon troll revenue landed on the West Coast during their respective periods. The distributions of vessel characteristics are shown in Figure 3.

[Figure 3 about here]

\subsection{Choice to fish}

For the model of general fishing behavior, all predictor variables were significant at the $p=0.05$ level, with the exception of the main effects of inertia and percent salmon troll, and the interaction between spatial closure/inertia (Figure 4). Inertia was not removed from the model because doing so resulted in the same AIC (15520). For the model of salmon troll fishing behavior, all predictors were significant at the $p=0.05$ level except the main effects of revenue, inertia, and center of gravity, and the interactions between spatial closure/revenue, spatial closure/number of years fished, and spatial closure/percent of revenue from salmon. The revenue terms were removed in the final model, as this resulted in a slightly lower AIC (11398 vs 11402; Figure 5). The AUC for the model of probability of fishing was 0.838 ( $95 \%$ DeLong confidence interval 0.832 0.845 ), and the AUC for the model of the probability of participating in the salmon troll fishery was 0.867 (95\% DeLong confidence interval 0.861-0.874), indicating good model fit in both cases. As the validation test set predictions were only based on fixed effects, these values likely slightly underestimate the fit of the models.

[Figure 4 and 5 about here]

\subsection{Predicted behavior and economic impacts}


In the absence of a closure, on average 1,332 $( \pm 11)$ vessels are expected to participate in fishing of any kind, and 1,159 $( \pm 14)$ are predicted to participate in the salmon troll fishery. In the case of a closure, 1,286 $( \pm 11)$ vessels are predicted to fish, and 1,000 $( \pm 13)$ are predicted to participate in the salmon troll fishery (Figure 6). With no closure, the focal vessels are predicted to generate $\$ 120.9( \pm 0.4)$ million in income, $\$ 242.4( \pm 0.8)$ million in sales, and 2,868 $( \pm 13)$ jobs. In contrast, with a closure, the focal vessels are predicted to generate $\$ 115.1( \pm 0.4)$ million in income, $\$ 229.6( \pm 0.9)$ in sales, and 2,661 $( \pm 13)$ jobs. This indicates that the current closure would result in a loss of $\sim \$ 5.8$ million in income, $\sim \$ 12.8$ million in sales, and 207 jobs (Figure 7).

[Figure 6 and 7 about here]

\subsection{Spatial impacts}

Unsurprisingly, the largest predicted relative economic impacts occur in the areas that are partly or entirely within the closed area. Coos Bay is most affected, with a $47 \%$ decrease in fishery related employment, $33 \%$ decrease in sales, and $31 \%$ decrease in income (Figures 8-10). Brookings, Eureka, and Fort Bragg also see considerable decreases. Though outside the closed area, Astoria, Bodega Bay, Crescent City, Monterey, Newport, and San Francisco also see relatively small declines. In Southern California and Washington, there is little predicted change associated with the closure scenario.

[Figures 8-10 about here]

\subsection{Comparison with deterministic predictions}

Cross-validation results indicate that the models tend to have a higher false positive than false negative rate, suggesting that the Monte Carlo results may over-predict overall participation. When using the optimal cutoff value, the models predict that without a closure, 1,210 vessels would fish, and of those, 916 would participate in the salmon troll fishery. In the case of a closure, the models predict that 1,136 vessels would fish, and 755 would participate in the salmon troll fishery (Figure 11). Without a closure, this method predicts the focal vessels would generate 2,960 jobs, \$123.5 million USD in income, and $\$ 248.0$ million USD in sales. In contrast, with the closure, the focal vessels are predicted to generate 2,632 jobs, $\$ 114.5$ million USD in income, and \$228.4 million USD in sales (Figure 12). Under these assumptions, the closure is predicted to result in a loss of 328 jobs, $\$ 8.9$ million in lost income, and $\$ 19.6$ million USD in sales. The distribution of spatial impacts were similar to the Monte Carlo predictions, with Coos Bay seeing a 49\% decrease in employment, $36 \%$ decrease in sales, and $34 \%$ decrease in income

[Figure 11and 12 about here]

\section{Discussion}

Predicting fisher responses to regulations and closures is complex, especially when participants have diverse fishing strategies, locations, sizes, and other characteristics [e.g. 19]. The methods used in this paper account for this heterogeneity by predicting whether vessels will participate in fishing based on a set of characteristics and behavior in prior years. The current closure is predicted to result in $\sim 50-75$ vessels not fishing at all, and a 
317 further $\sim 160$ fishing but not participating in the salmon troll fishery. This then has

318 important consequences for jobs, income, and local economies. These results suggest that

319 these impacts are distributed unevenly across vessels and across space, with less diversified vessels and vessels more dependent on salmon being most vulnerable. Vessels and communities inside the closed area are unsurprisingly most affected, with Coos Bay area communities seeing up to $\sim 50 \%$ declines in fisheries-related employment and up to $\sim 35 \%$ declines in fishing-related income and sales relative to predicted non-closure values. This has the potential to have large effects on local communities, as the commercial fishing industry provides $2-20 \%$ of net earnings in Oregon coastal communities [21]. As the third-largest fishing port in Oregon in terms of both volume and revenue [21], Coos Bay and the surrounding communities appear to be the hardest-hit by the closure.

Though past closures can prove useful in predicting future impacts, there are important differences between past closures and the current closure. The spatial extent of the 2017 closure is much smaller than that of 2008-2009, and as a result, the impact on salmon troll vessels appears to be somewhat smaller. In 2008-9, nearly half of focal vessels ceased fishing during that time, while only $\sim 14-24 \%$ are predicted not to fish in 2017. This is somewhat similar to the 2006 closure, when $27 \%$ of focal vessels did not fish at all (Figure 13). Though the extent of the 2017 closure is similar to that in 2006, the conditions in the years preceding the closures differed. From 2001-2005, ocean salmon catches were relatively good, averaging $>9.3$ million pounds per year, dropping to 2.3 million in 2006. In contrast, from 2012-2016, salmon catches were generally poor, averaging 4.4 million pounds per year, with 2016 being a particularly bad year with total landings of 1.6 million pounds. Thus, the 2017 closure is somewhat unique in that it follows a set of poor years, and these models may not fully capture the effects of a closure following a sequence of poor years, as 2016 already saw a large drop in vessel participation (Figure 13).

\section{[Figure 13 about here]}

The lack of fishing participation predicted in this analysis during closures seems to reflect broader trends in West Coast fisher responses to closures. A recent survey ${ }^{1}$ of West Coast fishers found that $79 \%$ had been affected by fishery closures in recent years. Of these fishers, only $40 \%$ said they responded to closures by participating in other fisheries, while $32 \%$ did work outside of commercial fishing and $35 \%$ did not do other work [20]. This indicates that the majority of fishers do not attempt to make up for income lost to closures by participating in other fisheries. Some fishers appear to choose to work in other industries during closures, which likely has wider economic impacts as they invest their time and resources in other activities.

This analysis focuses on the effects of the ocean closure and does not account for the conditions in other fisheries such as the commercial gillnet fishery. The gillnet fishery is active in rivers or estuaries, so it is not a mixed-stock fishery, and therefore is not

\footnotetext{
${ }^{1}$ Results are derived from a survey of vessels owners West Coast commercial fishing conducted in April 2017 by Washington Sea Grant and the Northwest Fisheries Science Center. The was a census of all active vessels and achieved a 50\% response rate with over 1400 completed surveys survey.
} 
usually affected by large-scale closures. However, low numbers of salmon returning to the Klamath Basin and elsewhere are likely to have significant economic effects on this fishery, especially as the fall Chinook fishery is closed on both the Klamath and Trinity Rivers in 2017. Recreational fishermen and associated businesses such as charter vessels and river guides are also likely to see negative effects. Together, this likely means that the necessary amount of disaster aid will be much higher than what is quantified here. For example, for the $2008-9$ disaster, only $\sim 40 \%$ of the disaster aid went to salmon trollers directly, with the rest going to gillnetters or other salmon-dependent businesses.

Outside of the closed area, the 2017 ocean regulations are predicted to have mixed, but generally negative effects on salmon ocean troll fishing. In most areas, the 2017 ocean troll regulations are expected to have relatively large negative impacts on income relative to 2016 and the 2012-2016 average [22]. However, north of Cape Falcon, Oregon and south of Pigeon Point, California, the impacts are likely to be positive. This analysis does not account for the effects of the season outside of the closure, so the total impacts on salmon troll fishing is likely to be more severe than documented here.

Understanding the behavior of fishers in the face of closures can help enable a faster and more efficient response to fishery disasters and potentially enable better adaptation to future changes and variability. The California Current ecosystem is inherently variable, and is likely to become more variable in the future [23], with potentially serious consequences for fisheries and associated businesses. As fishers move among fisheries in response to ecological and regulatory changes, changes in one fishery may influence the profitability and sustainability of other fisheries that are not directly liked ecologically via changes in fisher behavior. Future planned work includes an integrated set of models linking fishing behavior and the population dynamics of key fish stocks under environmental variability to create a coupled ecological-economic simulation model of West Coast fisheries.

Acknowledgements: This work was funded by the National Oceanic and Atmospheric Administration, the Joint Institute for the Study of the Atmosphere and Ocean, and the National Science Foundation (grant number 1616821). Funding sources were not involved in the study design, analysis, or writing of this paper or the decision to submit the article for publication.

\section{References}

[1] California Department of Fish and Wildlife. Status of the fisheries report: an update through 2011. Report to the California Fish and Game Commission as directed by the Marine Life Management Act of 19982013.

[2] Richerson K, Holland DS. Quantifying and predicting responses to a US West Coast salmon fishery closure. ICES Journal of Marine Science. 2017;DOI:

10.1093/icesjms/fsx093.

[3] Ackerman R, Neuenfeldt R, Eggermont T, Burbidge M, Lehrman J, Wells N, et al. Resilience of Oregon Coastal Communities in Response to External Stressors: University of Michigan; 2016.

[4] Fulton EA, Smith AD, Smith DC, van Putten IE. Human behaviour: the key source of uncertainty in fisheries management. Fish and Fisheries. 2011;12:2-17. 
[5] Wilen JE, Smith MD, Lockwood D, Botsford LW. Avoiding surprises: incorporating fisherman behavior into management models. Bulletin of Marine Science. 2002;70:55375.

[6] Lehman B, Huff DD, Hayes SA, Lindley ST. Relationships between Chinook Salmon Swimming Performance and Water Quality in the San Joaquin River, California.

[7] Hwan JL, Fernández-Chacón A, Buoro M, Carlson SM. Dry season survival of juvenile salmonids in an intermittent coastal stream. Canadian Journal of Fisheries and Aquatic Sciences. 2017; In press.

[8] Gómez-Ocampo E, Gaxiola-Castro G, Durazo R, Beier E. Effects of the 2013-2016 warm anomalies on the California Current phytoplankton. Deep Sea Research Part II: Topical Studies in Oceanography. 2017;In Press.

[9] Hare SR, Mantua NJ, Francis RC. Inverse production regimes: Alaska and West Coast Pacific salmon. Fisheries. 1999;24:6-14.

[10] Mantua NJ, Hare SR, Zhang Y, Wallace JM, Francis RC. A Pacific interdecadal climate oscillation with impacts on salmon production. Bulletin of the american Meteorological Society. 1997;78:1069-79.

[11] Peterson W, Bond N, Robert M. The Blob is gone but has morphed into a strongly positive PDO/SST pattern. PICES Press. 2016;24:46-7.

[12] NOAA Fisheries. Fishery Disaster Assistance.

[13] Upton HF. Commercial Fishery Disaster Assistance. Congressional Research Service Order Code RL34209. 2008.

[14] Zuur A, Ieno E, Walker N, Saveliev A, Smith G. Mixed effects models and extensions in ecology with R. New York, NY: Spring Science and Business Media; 2009. [15] Schielzeth H. Simple means to improve the interpretability of regression coefficients. Methods in Ecology and Evolution. 2010;1:103-13.

[16] Swets JA. Measuring the accuracy of diagnostic systems. Science. 1988;240:128593.

[17] Steinback SR. Using ready-made regional input-output models to estimate backward-linkage effects of exogenous output shocks. The Review of Regional Studies. 2004;34:57-71.

[18] Leonard J, Watson P. Description of the input-output model for Pacific Coast Fisheries (IOPAC). NOAA Technical Memorandum NMFS-NWFSC. 2011;111:1-64. [19] Zhang J, Smith MD. Heterogeneous response to marine reserve formation: a sorting model approach. Environmental and Resource Economics. 2011;49:311-25.

[20] Holland DS. Personal communication. 2017.

[21] The Research Group, LLC with assistance from the Coastal Oregon Marine Experiment Station. Oregon Commercial Fishing Industry in 2015, Briefing Report. Prepared for Oregon Department of Fish and Wildlife; 2016. [22] Pacific Fishery Management Council. Preseason Report III: Council Adopted Management Measures and Environmental Assessment Part 3 for 2017 Ocean Salmon Fishery Regulations: RIN 0648- XD843. (Document prepared for the Council and its advisory entities.). Pacific Fishery Management Council, 7700 NE Ambassador Place, Suite 101, Portland, Oregon 97220-1384.; 2017. 
449 [23] Black BA, Sydeman WJ, Frank DC, Griffin D, Stahle DW, García-Reyes M, et al. 450 Six centuries of variability and extremes in a coupled marine-terrestrial ecosystem.

451 Science. 2014;345:1498-502.

452 
Figure captions

Figure 1. Total West Coast salmon troll nominal ex-vessel revenue (a) and landings (b).

Figure 2. Map of port groupings and features included in this analysis. Vertical lines show the latitudinal extent of salmon ocean fishery closures that occurred between 2006 and 2017.

Figure 3. Vessel characteristic densities of focal vessel groups defined over 2001-2005 and 20122016. Note that 7 vessels with $>600,000$ USD in mean revenue and 31 vessels with latitudinal inertia $>10$ that were included in the analysis were excluded from their respective plots for visual clarity.

Figure 4. Coefficient estimates from model of choice to fish.

Figure 5. Coefficient estimates from model of choice to participate in the salmon troll fishery.

Figure 6. Predicted numbers of focal vessels active in fishing and in the salmon troll fishery under closure and no closure scenarios using the simulation approach.

Figure 7. Predicted total economic impacts of focal vessels under closure and no closure scenarios using the simulation approach.

Figure 8. Simulated predicted employment under closure and no closure scenarios.

Figure 9. Simulated predicted income under closure and no closure scenarios.

Figure 10. Simulated predicted sales under closure and no closure scenarios.

Figure 11. Predicted numbers of focal vessels active in fishing and in the salmon troll fishery under closure and no closure scenarios using the deterministic approach.

Figure 12. Predicted total economic impacts of focal vessels under closure and no closure scenarios using the deterministic approach.

Figure 13. Number of focal vessels active each year in a) any fishery and b) the salmon troll fishery. Two groups of vessels are shown; the 2001-2005 group was identified as the group participating in salmon troll over 2001-2005, and the 2012-2016 vessels were identified as those participating in salmon troll over 2012-2016. Total number of vessels that had any salmon troll landings each year are shown for reference. 

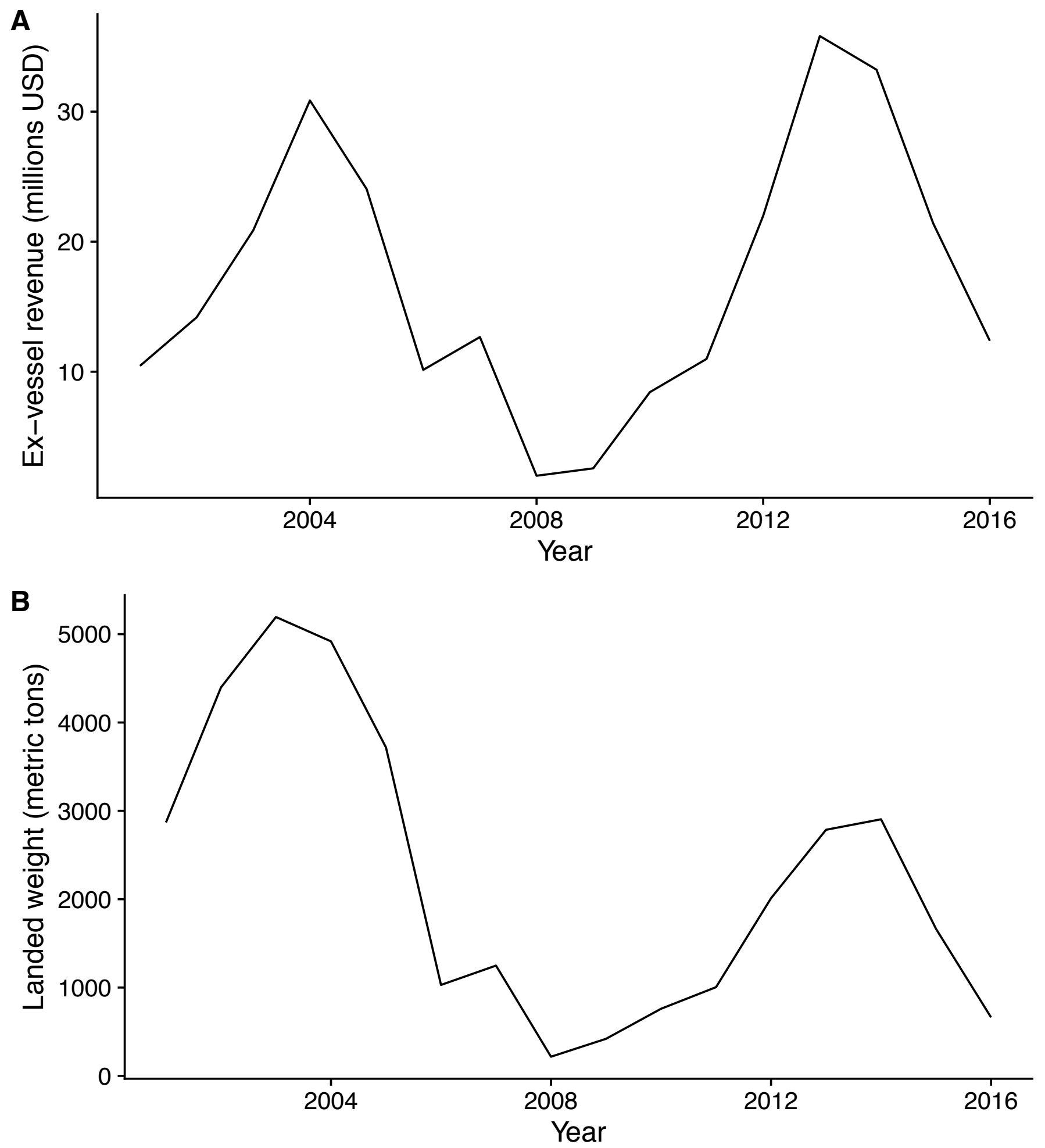


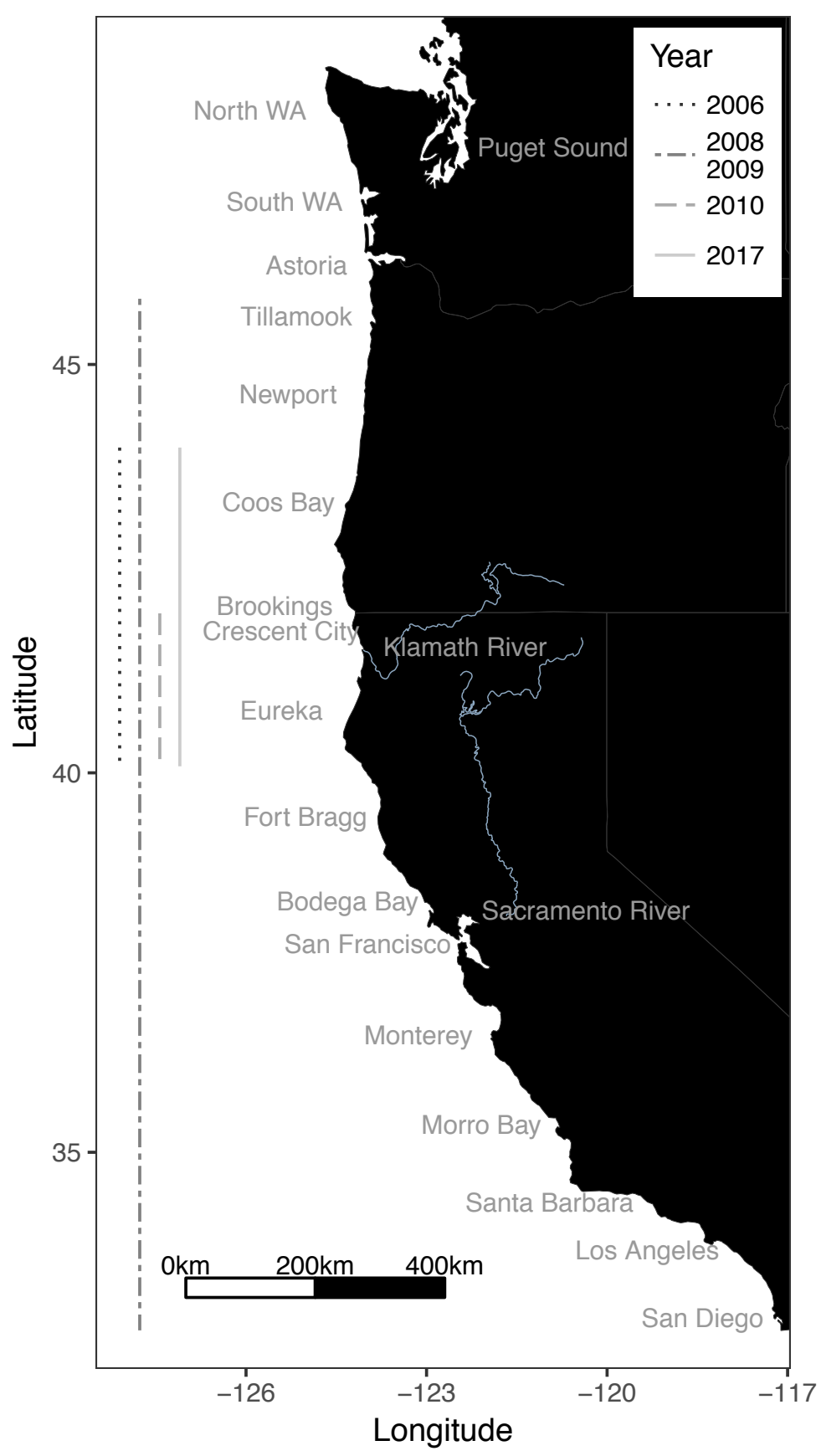




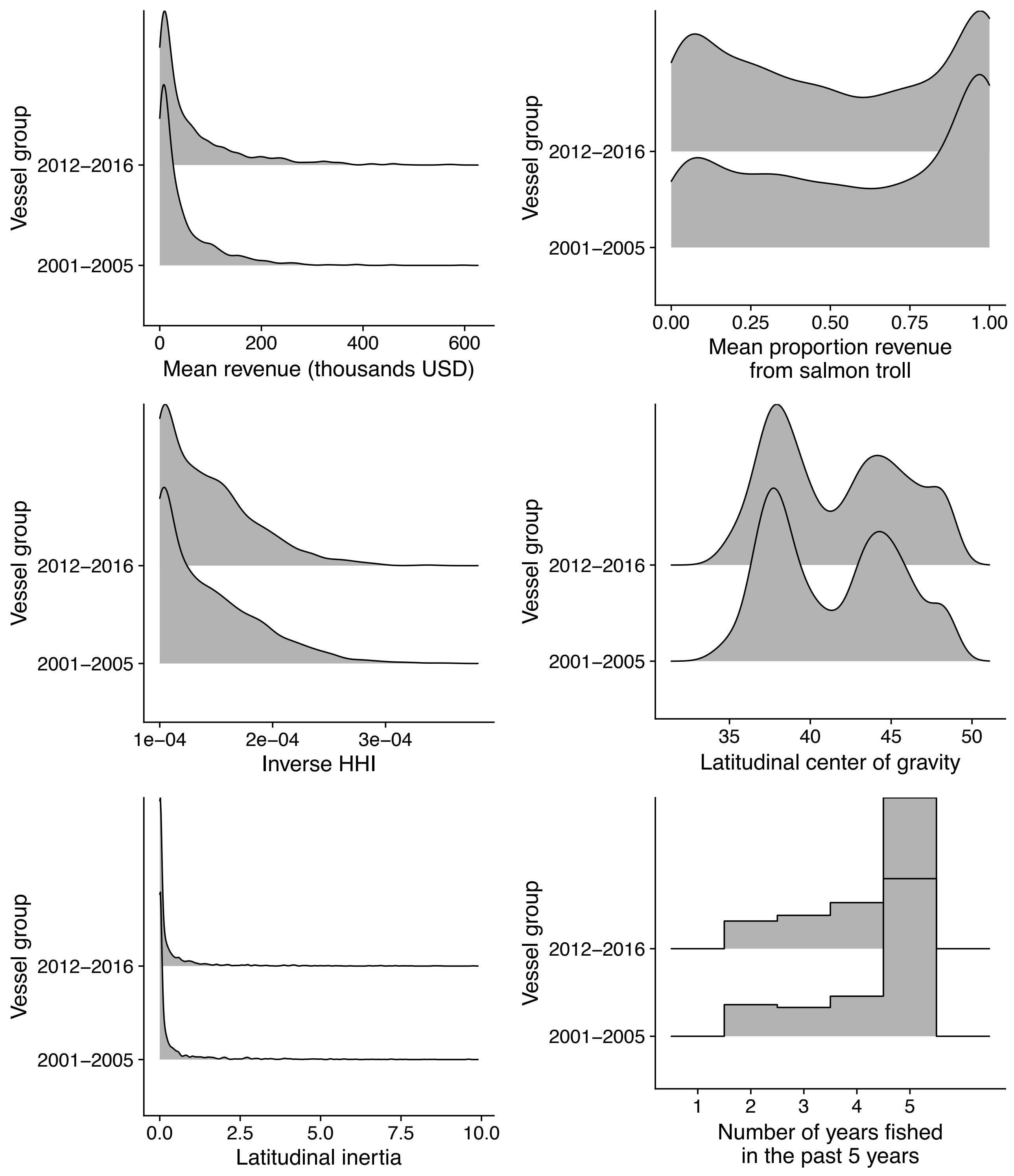




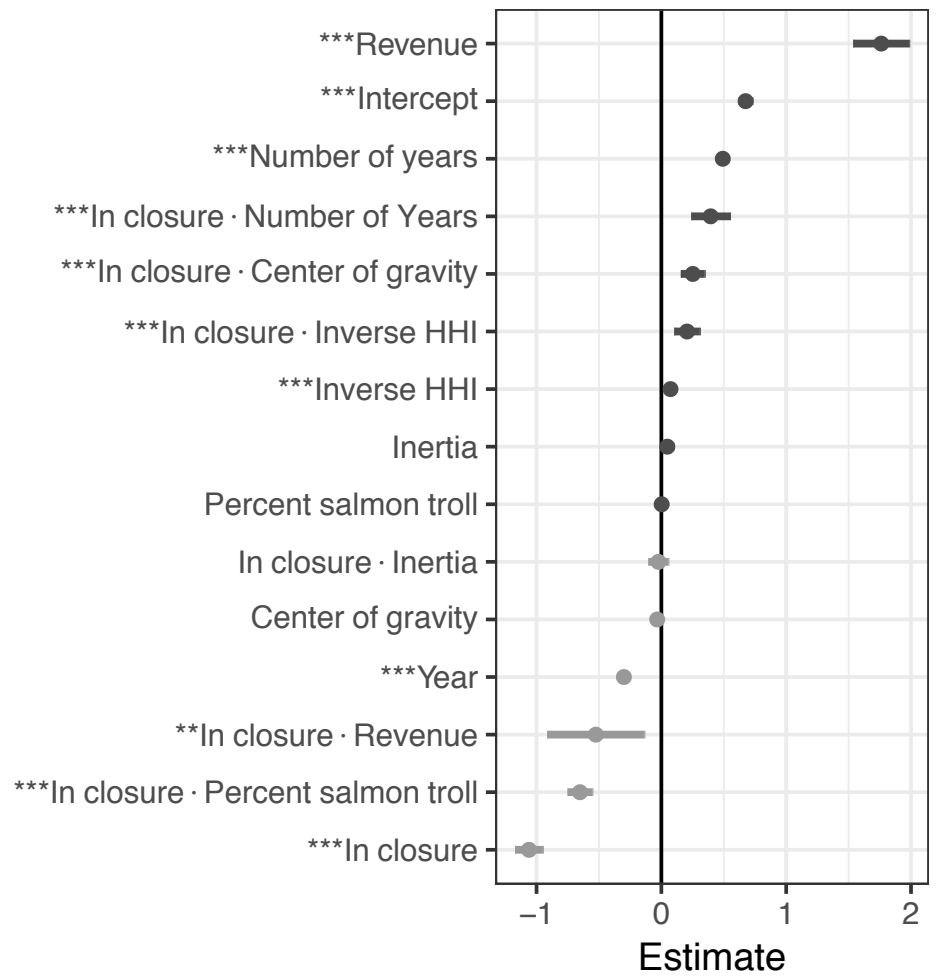




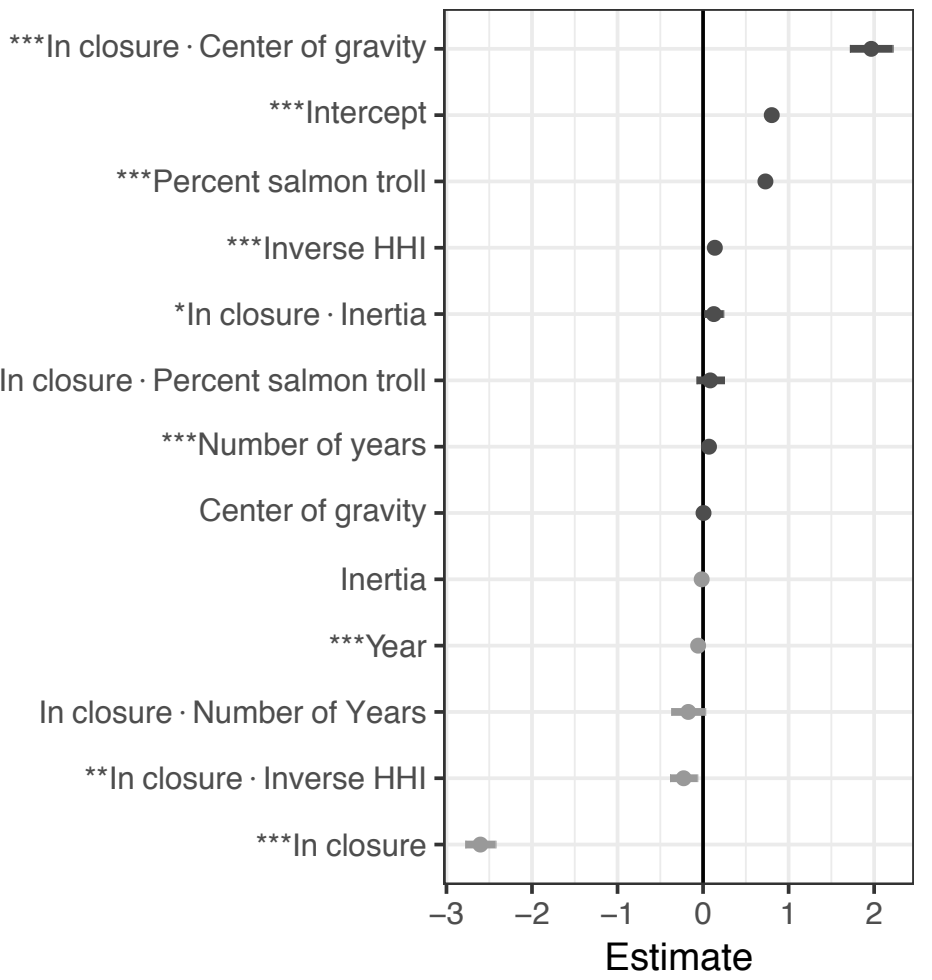



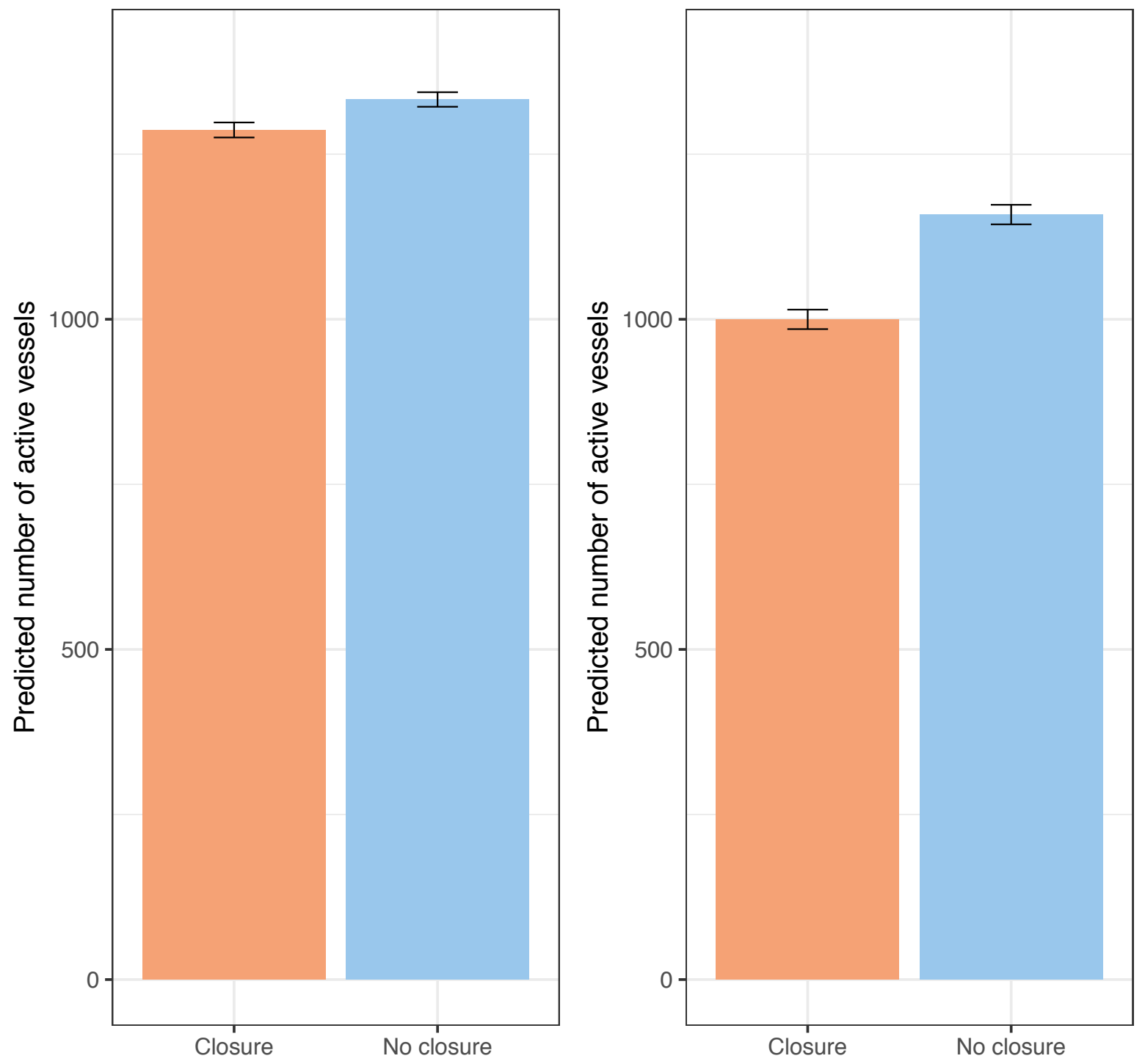
Employment

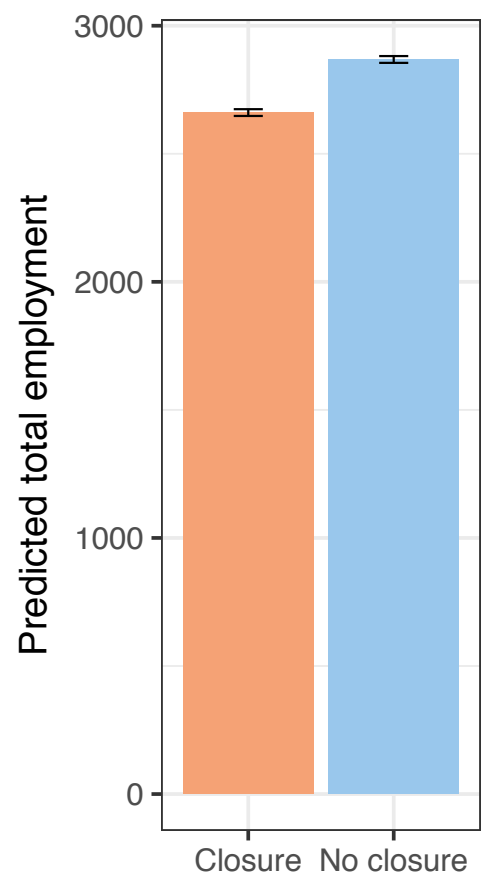

Income

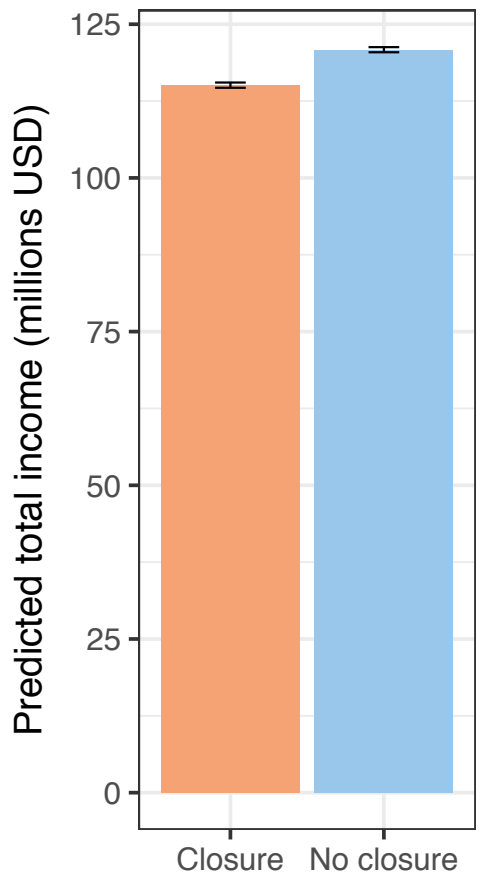

Sales

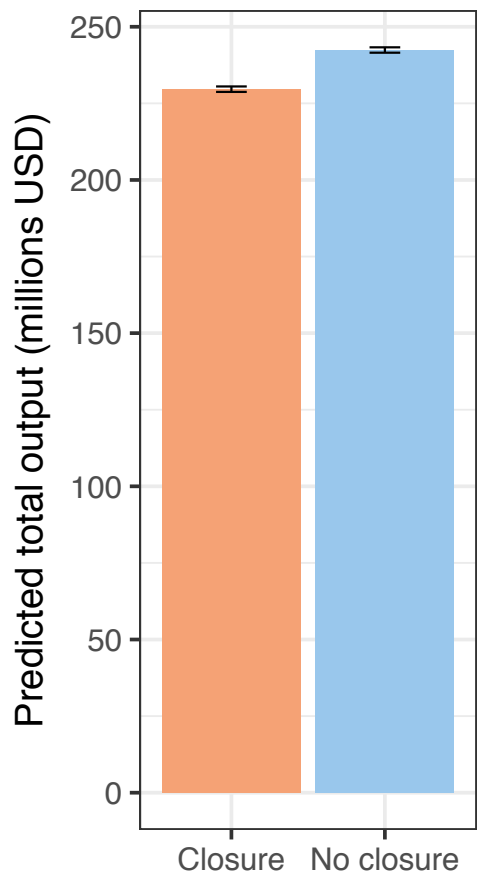




\section{Employment}

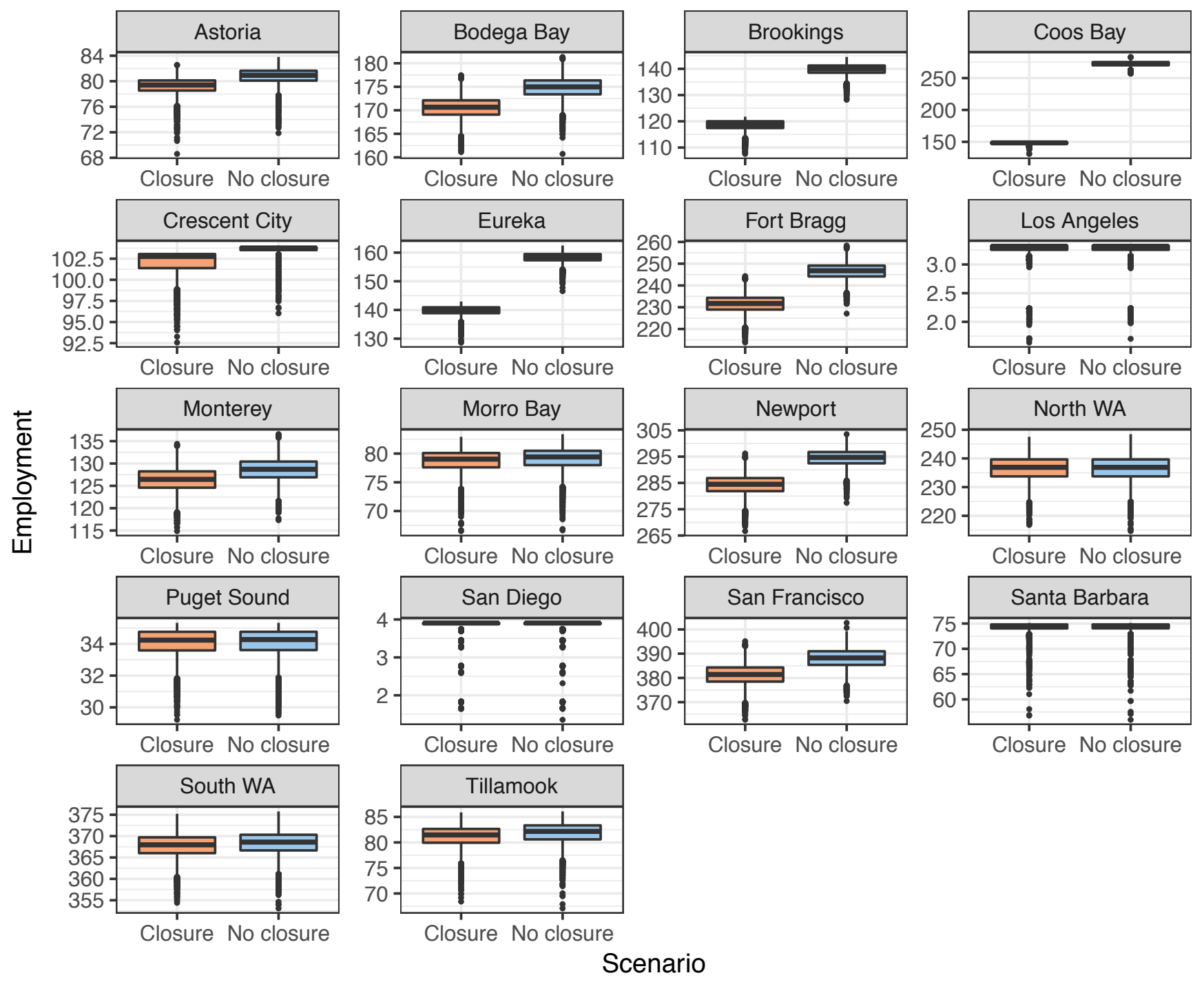


Income

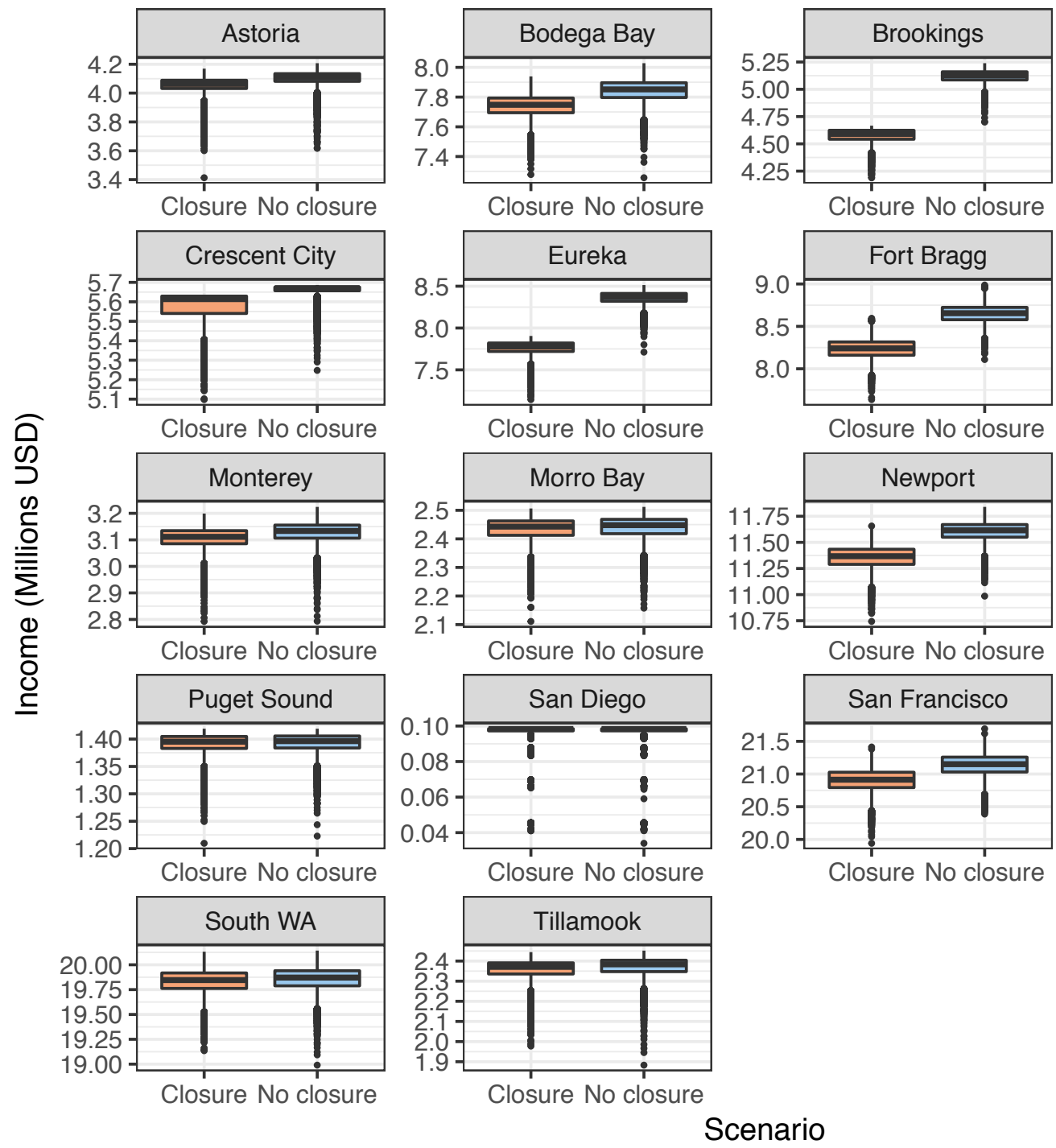

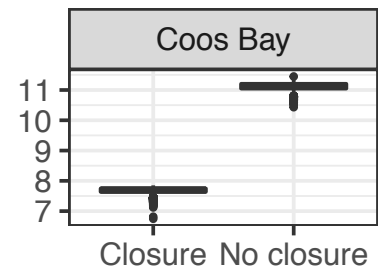

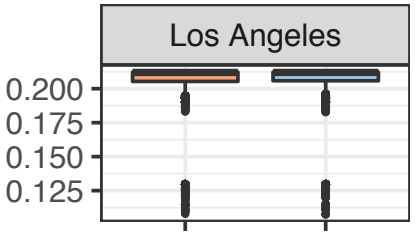

Closure No closure
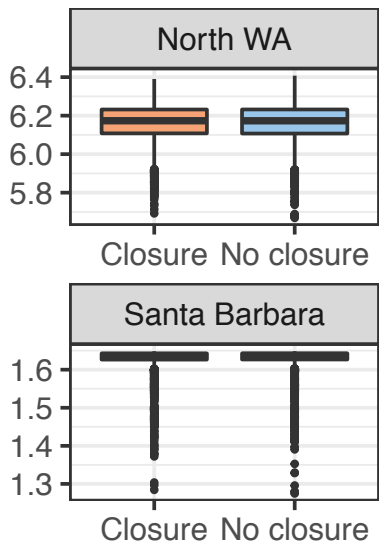


\section{Sales}

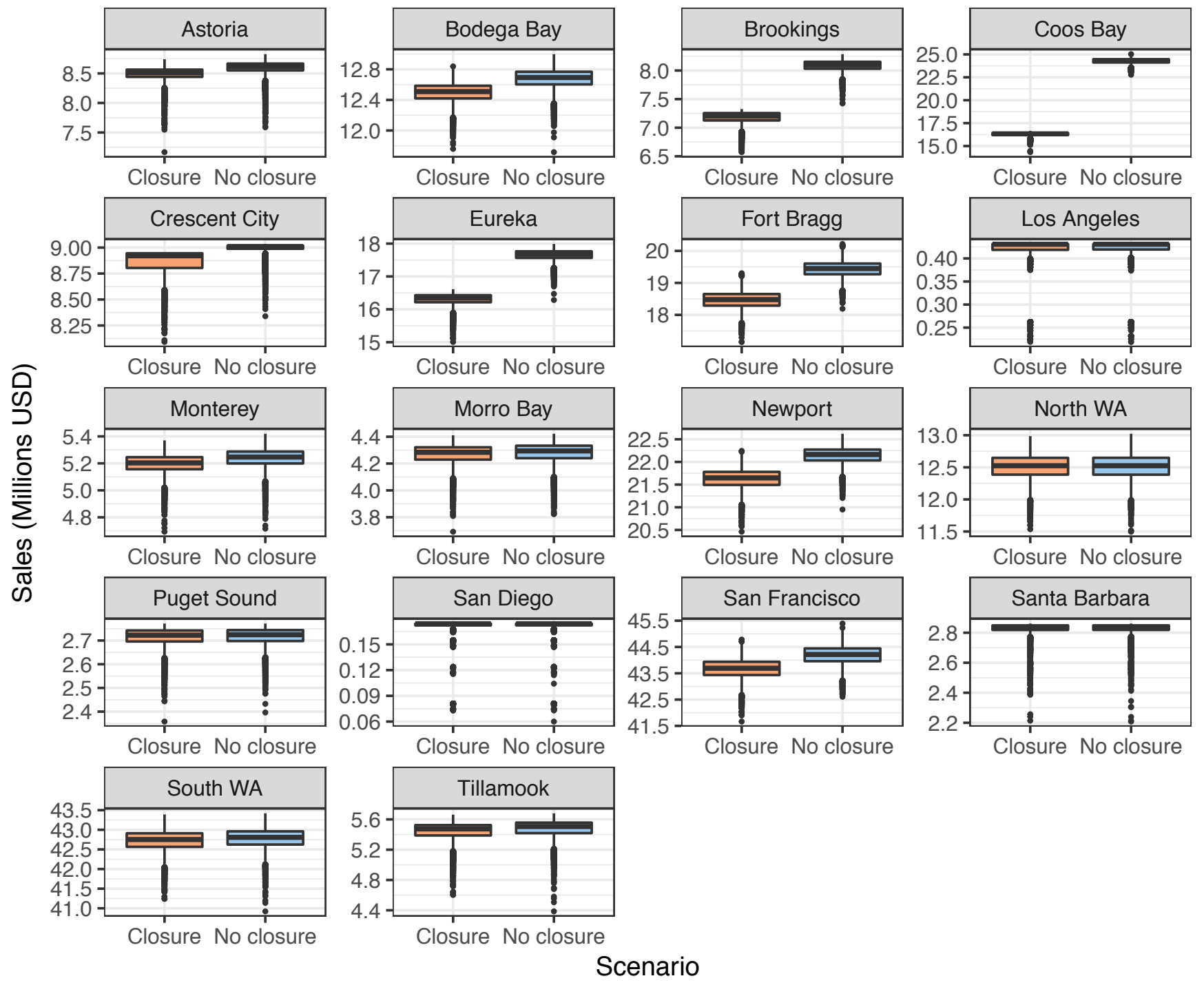


All fisheries

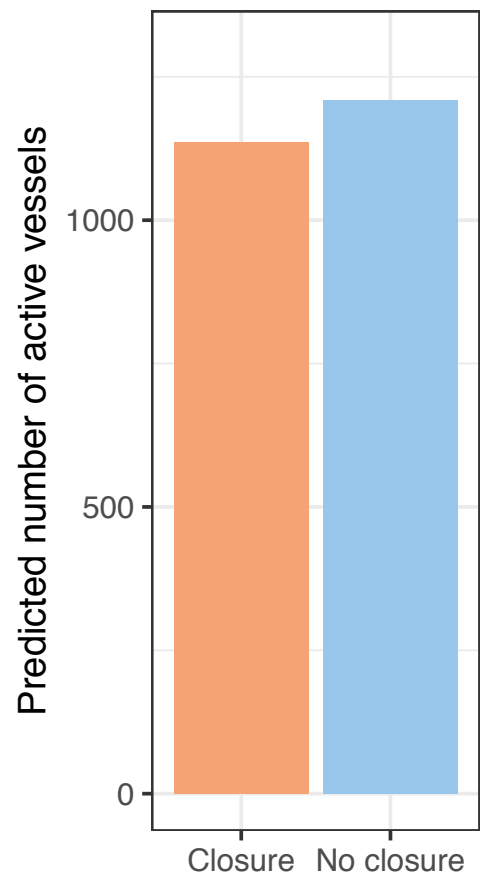

\section{Salmon troll}

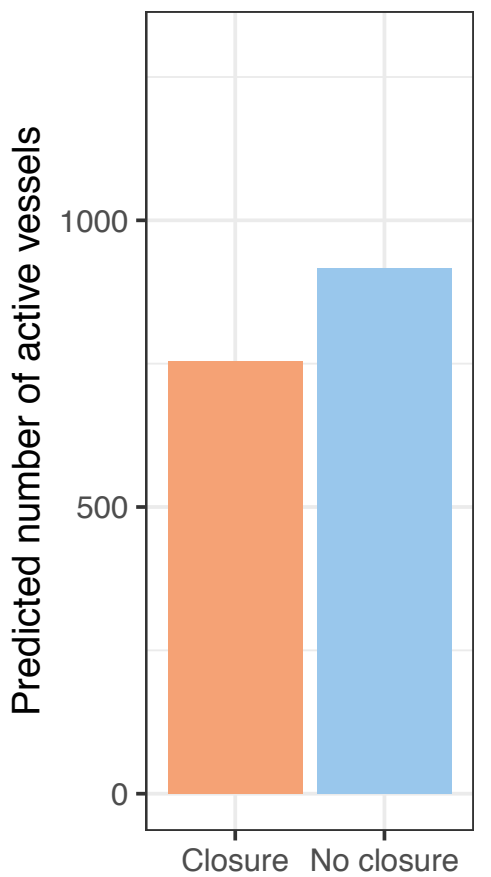




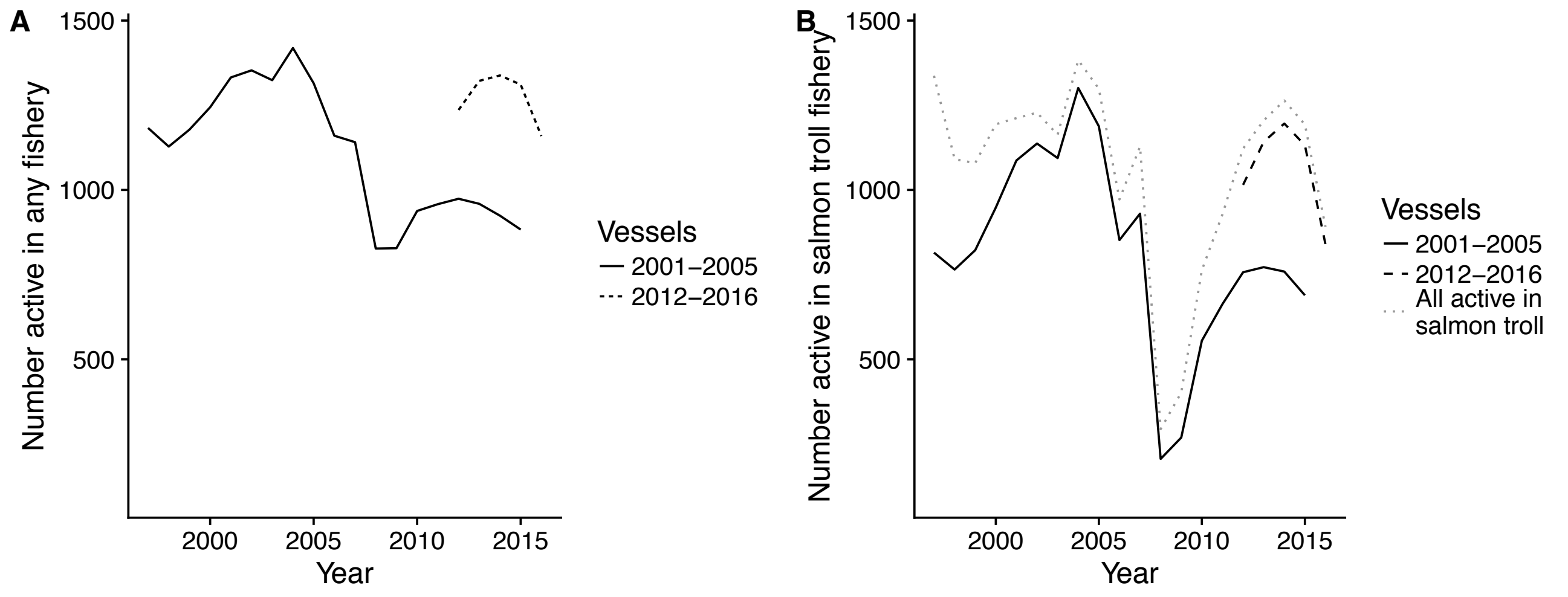


Table 1. Description of closures in the West Coast salmon ocean fishery since 2001.

\begin{tabular}{|l|l|l|}
\hline Season & Closed area & Cause \\
\hline 2006 & $\begin{array}{l}\text { Florence South Jetty to Horse } \\
\text { Mountain }\end{array}$ & Klamath river fall Chinook \\
\hline 2008 & South of Cape Falcon & Sacramento River fall Chinook \\
\hline 2009 & South of Cape Falcon & Sacramento River fall Chinook \\
\hline 2010 & $\begin{array}{l}\text { OR/CA border to Horse } \\
\text { Mountain }\end{array}$ & Sacramento River fall Chinook \\
\hline 2017 & $\begin{array}{l}\text { Florence South Jetty to Horse } \\
\text { Mountain }\end{array}$ & Klamath River fall Chinook \\
\hline
\end{tabular}

